\title{
METHOD OF RESOURCE QUEUES IN WORKING CAPITAL MANAGEMENT SYSTEM OF AGRICULTURAL ENTERPRISE
}

\author{
Oleg Kurlikov' ${ }^{1}$, Anna Volkonskaya ${ }^{1}$, Oksana Mamai ${ }^{1}$, Velta Parsova ${ }^{2}$ \\ ${ }^{1}$ Samara State Agrarian University, Russia; \\ ${ }^{2}$ Latvia University of Life Sciences and Technologies, Latvia \\ kurlikov_oi@ssaa.ru,volkonskaya_ag@ssaa.ru,mamai_ov@ssaa.ru,velta@parsova.lv
}

\begin{abstract}
The critical state of the provision of fixed assets and working capital is one of the main factors of regression of all processes of socio-economic development of the village and enterprises of the agro-industrial complex. Currently, there are various approaches to solving this problem: federal leasing, repair and restoration of equipment, transition to new technologies and machines, development of advanced forms of equipment operation, long-term and short-term loans. Unfortunately, none of these approaches can solve the problem of the lack of fixed and working capital in the countryside. Moreover, the economic condition of many agricultural enterprises is such that for them some of the listed paths are not always accessible. Therefore, it becomes necessary to develop a new method - the method of resource queues, which helps optimally operate agricultural enterprises in crisis conditions. Thus, the purpose of the study is to study the patterns of formation of working capital (spare parts for agricultural machinery, fuel, lubricants, etc.) and substantiation of directions for increasing the economic efficiency of their use. As a result of the study, the composition and structure of working capital and their sources were analyzed; an analysis of the efficiency of using working capital was carried out. The authors proposed a method of resource queues, which allows to reduce production costs in low-profit or unprofitable enterprises in the context of anticrisis management. The implementation of the planned measures will allow enterprises of the agricultural sector to reduce on average the cost of goods sold by at least $5 \%$ and increase revenue from sales of products by more than $6 \%$, which will also increase the profitability of production.
\end{abstract}

Keywords: potential, efficiency, technology, agriculture, working capital, resource queues.

\section{Introduction}

The financial position of agricultural enterprises in the Russian Federation and indicators of the efficiency of the use of working capital have deteriorated significantly in recent years. In the main sectors of the economy, the results of financial activities of enterprises differ sharply. So, the main part of the profit obtained in the region as a whole falls on the industries that serve agriculture and process agricultural products.

Over the past years, the disposal of fixed assets as a result of wear and tear significantly exceeded their supply to agriculture. The lack of machinery in the countryside, one way or another, leads to the curtailment of agricultural production. An indicator of this phenomenon is the reduction of arable land. So, for the period 2000-2019, the area of arable land in the country decreased by $11 \%$.

The lack of agricultural machinery leads not only to a reduction in areas, but also to violation of the timing of agrotechnical works. The timing of harvesting grain crops has increased over the past ten years by an average of 10-12 days. Grain losses due to lack of combine harvesters, according to the Ministry of Agriculture of Russia, amounted to about 15 million tons in 2019.

Practice shows that an increasing number of enterprises are insolvent. This does not allow them to pay taxes, make payments to off-budget funds, settle accounts with creditors and organize normal production activities. Difficulties with the sale of products, the most acute problems with the use of fixed assets due to their high cost and incomplete workload in recent years, the accumulation of working capital, along with weak settlement and payment discipline have led to a decrease in the level of profitability in agriculture.

During the period from 2010 to 2019, there were some changes in the structure of property of agricultural enterprises. There is a steady trend towards a decrease in the share of working capital in the structure of property in 2019 compared to 2010 by 3.6 points. This is mainly due to a decrease in the share of reserves - by 4 points. Therefore, it is necessary to consider more detailed changes that have occurred in the structure of the working capital itself.

Such an unfavorable situation with working capital is one of the reasons for the solvent crisis in the country, therefore the problem of managing these funds is becoming crucial in modern conditions. The main task of organizing working capital is to ensure the normal course of production with the smallest possible amount. Consequently, for stable operation of agricultural enterprises, not only the absolute 
size of circulating assets, but also their share in their structure are of great importance [1]. Analysis of the structure of circulating assets makes it possible to quantitatively characterize not only the various aspects of their use, but also the course of the material reproduction process through an assessment of the size of the balances of circulating assets that are constantly formed at each of its stages.

Thus, the critical state of the provision of fixed and circulating assets is one of the main factors of regression of all processes of socio-economic development of agricultural enterprises. The current approaches to solving this problem: federal leasing, repair and restoration of equipment, the transition to new technologies and machines, the development of advanced forms of equipment operation, longand short-term loans, etc. are not always available. Therefore, it becomes necessary to consider a new method - the method of resource queues, which helps optimally navigate agricultural enterprises in the conditions of anti-crisis management.

\section{Materials and methods}

This study was based on the following methods: the method of resource queues, based on the comparison of costs that make up the cost of production; the method of strategic systems analysis, which allows to identify typical problems of modern agricultural enterprises. The study is based on the data from the Ministry of Economic Development of the Russian Federation, the Ministry of Agriculture of the Russian Federation, and the Federal State Statistics Service.

\section{Results and discussion}

The crisis state of agricultural production is largely due to the lack of the working capital (Table 1). The loss of own working capital in agriculture occurred due to the inflationary factor in the economy, price disparity and as a result of an increase in the number of unprofitable enterprises that failed to adapt to the conditions of the market economy.

Table 1

\section{Structure of working capital of agricultural enterprises of the Russian Federation} (on average over the last 5 years), \%

\begin{tabular}{|l|c|c|c|c|c|c|}
\hline \multirow{2}{*}{ Indicator } & \multicolumn{7}{c|}{ Years } \\
\cline { 2 - 7 } & 2014 & 2015 & 2016 & 2017 & 2018 & 2019 \\
\hline Fixed assets & 92.1 & 88.4 & 88.7 & 90.5 & 90.9 & 92.0 \\
\hline Working capital - total, & 7.9 & 11.6 & 11.3 & 9.5 & 9.1 & 8.0 \\
\hline $\begin{array}{l}\text { including: } \\
\text { Stocks - total, of which }\end{array}$ & 5.9 & 8.6 & 7.9 & 6.8 & 5.4 & 4.6 \\
\hline - productive reserves & 4.3 & 6.2 & 4.8 & 4.9 & 3.1 & 1.9 \\
\hline - work in progress costs & 1.1 & 1.6 & 2.1 & 1.4 & 1.5 & 0.3 \\
\hline - finished products & 0.4 & 0.6 & 0.9 & 0.3 & 0.3 & 1.5 \\
\hline - broths shipped & 0.0 & 0.0 & 0.0 & 0.0 & 0.1 & 0.1 \\
\hline - other supplies and costs & 0.1 & 0.2 & 0.1 & 0.2 & 0.4 & 0.8 \\
\hline Receivables & 1.3 & 2.0 & 2.2 & 1.6 & 2.4 & 2.1 \\
\hline Short-term financial investments & 0.0 & 0.0 & 0.0 & 0.2 & 0.2 & 0.5 \\
\hline Cash & 0.0 & 0.1 & 0.2 & 0.3 & 0.4 & 0.7 \\
\hline Other working capital & 0.7 & 0.9 & 1.0 & 0.6 & 0.7 & 0.1 \\
\hline TOTAL & 100.0 & 100.0 & 100.0 & 100.0 & 100.0 & 100.0 \\
\hline
\end{tabular}

The main task of organizing the working capital is to ensure a normal course of production with the smallest possible amount [2]. Consequently, for stable operation of agricultural enterprises, not only the absolute size of circulating assets, but also their share in their structure are of great importance.

Analysis of the structure of circulating assets makes it possible to quantitatively characterize not only the various aspects of their use, but also the course of the material reproduction process through an assessment of the size of the balances of circulating assets that are constantly formed at each of its stages.

As it can be seen from Table 2, in the structure of working capital, which had developed by the beginning of 2020, the economy is undergoing serious changes: $31.0 \%$ of their total amount were invested in inventories in 2019, while $40.7 \%$ were diverted into accounts receivable, in industry these 
indicators were equal to $37.3 \%$ and $38.8 \%$, respectively. In agriculture, there is a decrease in inventories by 10.1 points, including inventories by 31.6 points. The share of accounts receivable has increased, and this is a negative phenomenon, since the process of diverting own circulating assets from the economic turnover is accompanied by indirect losses in the company's income.

Table 2

Dynamics of the composition and structure of working capital in the Russian economy, \%

\begin{tabular}{|l|c|c|c|c|c|c|}
\hline \multirow{2}{*}{\multicolumn{1}{|c|}{ Types of working capital }} & \multicolumn{7}{c|}{ Years } \\
\cline { 2 - 7 } & 2014 & 2015 & 2016 & 2017 & 2018 & 2019 \\
\hline Stocks - total, of which & 19.0 & 26.7 & 30.6 & 29.6 & 32.6 & 31.0 \\
\hline - productive reserves & 10.7 & 15.0 & 17.8 & 17.3 & 15.8 & 16.6 \\
\hline - work in progress costs & 3.9 & 4.7 & 5.7 & 5.5 & 6.9 & 5.9 \\
\hline - finished products & 3.1 & 5.2 & 5.3 & 5.1 & 7.1 & 5.8 \\
\hline - broths shipped & 1.0 & 1.4 & 1.3 & 0.8 & 0.8 & 0.5 \\
\hline - other supplies and costs & 0.3 & 0.4 & 0.5 & 0.9 & 2.0 & 2.2 \\
\hline Receivables & 54.6 & 49.4 & 45.5 & 45.0 & 42.2 & 40.7 \\
\hline Short-term financial investments & 7.2 & 11.1 & 10.6 & 7.7 & 6.0 & 8.7 \\
\hline Cash & 1.6 & 2.8 & 3.1 & 3.2 & 3.7 & 3.2 \\
\hline Other working capital & 17.6 & 10.0 & 10.2 & 14.5 & 15.5 & 16.4 \\
\hline TOTAL & 100.0 & 100.0 & 100.0 & 100.0 & 100.0 & 100.0 \\
\hline
\end{tabular}

Consideration of the composition and structure of circulating assets, their placement at different stages of the circulation makes it possible to correctly assess the proportions that have developed between the individual elements that form the circulating production assets and circulation funds [3]. Violation of the proportionality and rational organization of the structure of circulating assets reduces the efficiency of their use, disrupts the continuity of the production process, and, consequently, the circulation of the advanced value. The structure of working capital that has developed in agricultural enterprises is largely predetermined by the peculiarities of the circulation of funds arising from the specifics of agricultural production itself [4].

Analysis of the cost of production of agricultural products made it possible to draw the following conclusions. Labor costs prevail in the structure of production costs. The share of these costs tends to increase in agricultural enterprises and can range from $22.8 \%$ to $37.1 \%$. For the period 2010-2019 the share of these costs averaged from 17 to $20 \%$, which is a similar indicator for the analyzed enterprises.

In production costs, along with wages, the largest place is occupied by material costs included in the cost of production, including the cost of seeds and planting material, feed, mineral fertilizers, oil products, electricity, fuel, spare parts. The share of material costs is, respectively, from $59.9 \%$ to $77.3 \%$. For the period 2010-2019 on average, the share of material costs ranges from 54\% to 69\%. The material costs for crop production are dominated by the costs of seeds and planting material.

The share of costs for petroleum products in the crop growing industry ranges from $8.4 \%$ to $32.7 \%$. It should be noted that the largest share of costs for oil products at agricultural enterprises is associated with an increase in prices for oil products on the market, which clearly affected the structure of costs for production.

The increase in prices was also reflected in spare parts - from $7.6 \%$ to $17.2 \%$, mineral fertilizers from $12.6 \%$ to $15.3 \%$. It should be noted that the share of depreciation costs decreased and ranged from $8.9 \%$ to $13.6 \%$. This decrease is due to a decrease in fixed assets due to their complete depreciation at agricultural enterprises.

In animal husbandry, there is a slight increase in labor costs with deductions for social needs and vary from $24.3 \%$ to $37.2 \%$. Among material costs, a significant share in animal husbandry is the cost of feed, where their share was from $41.3 \%$ to $52 \%$.

Thus, on the basis of the above, we can say that the composition of the working capital of enterprises is quite diverse. These include production inventories, cash and accounts receivable. Therefore, in our opinion, a rational structure of working capital is very important in order to use it efficiently. 
The critical state of the provision of fixed and circulating assets is one of the main factors of regression of all processes of socio-economic development of the village and enterprises of the agroindustrial complex [5]. Currently, there are various approaches to solving this problem: federal leasing, repair and restoration of equipment, the transition to new technologies and machines, the development of progressive forms of equipment operation, long- and short-term loans, etc. Note that none of the above approaches can solve the problem of the lack of fixed and working capital in the countryside. Moreover, the economic condition of many agricultural enterprises is such that for them some of the listed routes are not always accessible. Therefore, there is a need to consider a new method - the method of resource queues, which helps optimally navigate agricultural enterprises in extreme conditions.

So, production, the ultimate goal of which is to make a profit, is described by the classical scheme of the circulation of capital (1).

$$
D-T \ldots P \ldots T_{1}-D_{1}(1)
$$

where $D_{1}, T_{1}$ - respectively monetary and commodity form of capital.

Within the framework of this scheme, real production can be in a profitable, conservative or unprofitable state. The first two states are characterized by the fact that the production costs are fully recouped by the manufactured products. In this case, the priority of restoring the spent production resources does not have any significance [6]. It is a different matter when incomes are lower than expenses. In this case, production resources occupy different positions in the queue for their reimbursement, that is, a so-called resource queue is formed.

The method of resource queues is a method in which, for various situations of their activities, the priorities of allocation and reimbursement of the main types of resources included in working capital are justified, which ensures the development of tactical measures when bringing enterprises out of a crisis state. To understand why and how the resource queue is formed, let us consider an example, for which we use the structure of the cost of production of spring wheat seeds that has developed on average in recent years (Table 3).

Table 3

Structure of the cost of production of spring wheat seeds

\begin{tabular}{|c|l|c|c|}
\hline Code & \multicolumn{1}{|c|}{ Naming of expenditures } & $\begin{array}{c}\text { Amount, } \\
\text { RUB} \cdot \mathbf{h a}^{-1}\end{array}$ & $\begin{array}{c}\text { Specific } \\
\text { weight, } \%\end{array}$ \\
\hline Dam & Depreciation of agricultural machinery & 216 & 2.5 \\
\hline De & Energy depreciation & 702 & 8.0 \\
\hline W & Wage & 2020 & 22.9 \\
\hline P & Payroll & 263 & 3.0 \\
\hline Sd & Seed dressing & 102 & 1.1 \\
\hline MF & Mineral fertilizers & 486 & 5.5 \\
\hline Ppp & Plant protection products & 1702 & 19.3 \\
\hline Re & Energy repair & 608 & 6.9 \\
\hline Ram & Agricultural machinery repair & 196 & 2.2 \\
\hline S & Seeds & 2107 & 23.9 \\
\hline F & Fuel & 410 & 4.7 \\
\hline TOTAL & & 8812 & 100.0 \\
\hline
\end{tabular}

If the proceeds from the sale of grain are more than the cost of its production, then the order of reimbursement of resources does not matter in principle. In this case, the revenue ensures the reimbursement of all resources in queue I (Fig. 1). If the proceeds are equal to the costs, then simple reproduction occurs. 

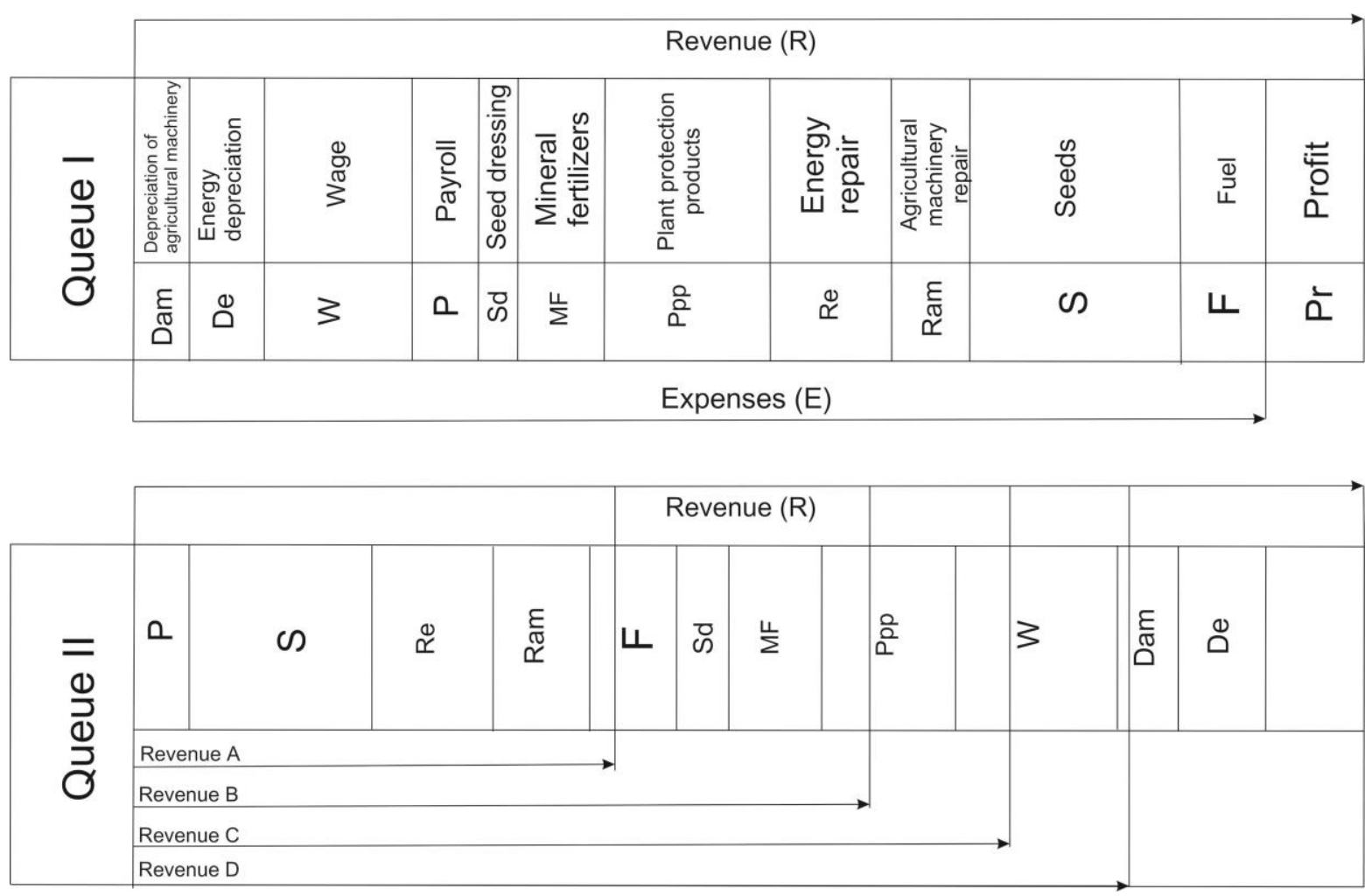

Fig. 1. Formation of a resource queue

Consider a situation where revenue does not cover costs. Then the question arises, which resources should be restored as a matter of priority, so that the reproduction process does not stop. Eleven resources in our example can generate 39916800 queue options. However, in reality, they form queues that are very close to those shown by us in queue II (Fig. 1).

The head of the enterprise develops in the created extreme conditions the optimal production management strategy aimed at its unconditional preservation of all resources. Each leader has his own vision of the problem and his own ways of solving them. However, on average, they all do what the external and internal economic situation dictates to them. Therefore, these queues can be considered as probabilistic and statistical, and the conclusions on them are fair on average.

The first place in the queue we are considering is always occupied by taxes $(\mathrm{P})$. Such a high ranking priority for this resource is ensured by the current tax legislation in the country, which unconditionally removes all tax arrears from the current account of any enterprise.

Further, there are resources, the absence of which leads to an immediate stop of production: seeds, repair of equipment and fuels and lubricants (S, Re, Ram, T). Mineral fertilizers (MF) and chemical plant protection products ( $\mathrm{Sd}, \mathrm{Ppp}$ ) belong to such a group of production resources, the absence of which does not stop the production process itself but, reduces the quantity and quality of products, closes the resource group of working and variable capital wages (W). Such a place of this resource in the queue for restoration indicates that in an extreme situation the interests of production have a higher priority.

The lowest rank priority is given to resources associated with depreciation and amortization of fixed assets (Dam, De). This is explained by the fact that fixed assets are converted into money in parts and gradually, which causes a long delay in their transformation into their original form.

From the point of view of self-preservation of production, queue II is the most efficient. The resources that are at the head of the queue provide the necessary conditions for the resumption of production, and those that stand at the end dampen the negative consequences of the resulting losses of the current year. An important conclusion for practice follows from this fact: the larger the depreciation fund of the enterprise, the higher its potential survivability in the conditions of market relations. Consider situations when revenue is less than costs (sections at points A, B, C and D).

Section $\mathrm{D}$. The section at point $\mathrm{D}$ shows such a situation when the received revenue restores all the resources to the left of point D (taxes and working capital). Depreciation of fixed assets in this case is 
not restored, or is partially restored. In addition, today many agricultural enterprises use the money of the amortization fund not for their intended purpose, and therefore, after the expiration of the amortization period, they have a large arrears in this fund.

In practice, the funds that are gradually accumulated in the amortization fund can be used by the company for any purpose, including to cover losses that arise. In essence, the amortization fund ensures the operation of the internal lending mechanism, which, unlike external lending, does not change the rank priorities of those resources for the restoration of which it is spent. This and only this is the huge protective function of the depreciation fund.

The presence of a depreciation fund and the volume of its annual replenishment enable the enterprise to function steadily when it enters the unprofitable zone. At the same time, the length of the permissible loss-making zone is fully determined by the amount of annual depreciation deductions. Enterprises that do not have their own equipment become extremely sensitive in a market economy to the occurrence of unprofitable situations.

Thus, considering depreciation deductions through the prism of resource queues, it is possible to effectively assess the stability of the enterprise to natural fluctuations in the market situation and its ability to adequately respond to them. It follows from this that in order to strengthen the enterprise, it is necessary to have a stable and replenished depreciation fund.

Section C. If the proceeds are received, which does not restore the resource "wages" (section C), then in order not to stop the production process, it is necessary to infringe on the rights and interests of the employees of the enterprise. This example explains many of the problems in our country associated with non-payment of wages to employees on time. At the same time, an interesting situation is observed, wages are not paid, and charges for it are transferred to state funds. It turns out that without receiving a salary, the employee has already paid off taxes with the state.

Section B. Revenue B proceeds go through resources, the non-recovery of which leads to a technology disruption. In our example, there is a shortage of the resource of "plant protection products", the absence of which, although it does not stop production, worsens the quality of products. At the same time, it is natural that the wage and depreciation funds are not replenished.

Section A. When the revenue A is only enough to cover taxes and some of the resources included in the critical group, then such a situation is inevitable to curtail production. Moreover, all the negative consequences described in the previous sections are manifested here with special force. From the considered example it is clear that within the working capital there are 3 groups of resources that have different effects on the production process, these are:

1. Resources, the absence of which reduces the volume (curtailing the production activity of the enterprise) of production: seeds, repair of equipment and fuel;

2. Resources, the absence of which preserves production, but leads to a violation of technology: dressing, mineral fertilizers and plant protection products;

3. Resources, the absence of which causes socio-economic problems: wages.

Thus, using the resource queue and the principle of allocating resources in it in various extreme market situations, the manager will be able to predict the strategy for bringing the enterprise out of a difficult state.

\section{Conclusions}

The above analysis and research showed:

1. During the period from 2010 to 2019 there were some changes in the structure of property of agricultural enterprises. There is a steady trend towards a decrease in the share of the working capital in the structure of property in 2019 compared to 2010 by 3.6 points. This is mainly due to a decrease in the share of reserves - by 4 points.

2. The unfavorable situation with the working capital is one of the reasons for the solvent crisis in the country, therefore the problem of managing these funds is becoming crucial in modern conditions.

3. The composition of the working capital of enterprises is quite diverse, therefore it is important to determine the rational structure of the working capital in order to use it efficiently. 
4. The critical state of the provision of fixed and circulating assets is one of the main factors of regression of all processes of socio-economic development of agricultural enterprises. The current approaches to solving this problem are not always available. Therefore, it becomes necessary to consider a new method - the method of resource queues, which helps optimally navigate agricultural enterprises in the conditions of anti-crisis management.

5. The method of resource queues is a method in which, for various situations of their activities, the priorities of allocation and reimbursement of the main types of resources included in working capital are justified, which ensures the development of tactical measures when bringing enterprises out of a crisis state.

6. Using the resource queue and the principle of allocating resources in it in various extreme market situations, the manager will be able to predict the strategy for taking the enterprise out of a difficult state. Using the properties of resource queues allows to make intelligent control decisions.

7. The resource queues method is still the only one, within which resources show us their dual nature, when the resources of the fixed capital acquire the properties of the working capital.

8. The resource queues method allows to solve a wide range of tasks for optimal management of lowprofit and unprofitable enterprises. This method can also be successfully used to manage highly profitable enterprises.

\section{References}

[1] Лысенко М., Лысенко Ю., Мингалев В., Шарапова В. Технический потенциал сельскохозяйственных организаций и его оптимизация (Technical potential of agricultural organizations and its optimization). Agrarian Bulletin of the Urals, vol. 12 (166), 2017, pp. 91-99. (In Russian).

[2] Клейнер Г.Б. Экосистема предприятия: внутренне наполнение и внешнее окружение (Enterprise ecosystem: internal content and external). Strategic Planning and Enterprise Development: Plenary Reports of the Nineteenth All-Russian Symposium, Moscow, 2019, pp. 613. (In Russian).

[3] Melece L., Hazners J. Factors influencing Latvian small and medium enterprises towards ecoinnovation. Proceedings of 16th international scientific conference "Engineering for rural development", Jelgava, 2017, pp. 1466-1473.

[4] Nipers A., Pilvere I., Krievina A., Bratka V. Projecting investments and fixed assets in agriculture in Latvia. Proceedings of 18th international scientific conference "Engineering for rural development", Jelgava, 2019, pp. 1779-1785.

[5] Belkina E., Zaytseva M., Galenko N., Volkonskaya A., Kurlykov O. Ecovillage as an instrument to attract the working population to the countryside. Indo American journal of pharmaceutical sciences, vol. 3, 2019, pp. 6243-6248.

[6] Zhichkin K., Nosov V., Zhichkina L. Economic mechanism of the machine-tractor park updating in the Samara region. IOP Conference Series: Earth and Environmental Science, vol. 403, 2019. p. 012073. 